Review

\title{
The regulation of matrix metalloproteinases and their inhibitors
}

\author{
Ian M. Clark *, Tracey E. Swingler, Clara L. Sampieri ${ }^{1}$, Dylan R. Edwards \\ School of Biological Sciences, University of East Anglia, Norwich NR4 7TJ, UK
}

Available online 24 December 2007

\begin{abstract}
The matrix metalloproteinases (MMP) are a family of 23 enzymes in man. These enzymes were originally described as cleaving extracellular matrix (ECM) substrates with a predominant role in ECM homeostasis, but it is now clear that they have much wider functionality. Control over MMP and/or tissue inhibitor of metalloproteinases (TIMP) activity in vivo occurs at different levels and involves factors such as regulation of gene expression, activation of zymogens and inhibition of active enzymes by specific inhibitors. Whilst these enzymes and inhibitors have clear roles in physiological tissue turnover and homeostasis, if control of their expression or activity is lost, they contribute to a number of pathologies including e.g. cancer, arthritis and cardiovascular disease. The expression of many MMPs and TIMPs is regulated at the level of transcription by a variety of growth factors, cytokines and chemokines, though post-transcriptional pathways may contribute to this regulation in specific cases. The contribution of epigenetic modifications has also been uncovered in recent years. The promoter regions of many of these genes have been, at least partly, characterised including the role of identified single nucleotide polymorphisms. This article aims to review current knowledge across these gene families and use a bioinformatic approach to fill the gaps where no functional data are available.
\end{abstract}

(C) 2007 Elsevier Ltd. All rights reserved.

Keywords: MMP; TIMP; Proteinase; Gene regulation; Promoter

\section{Contents}

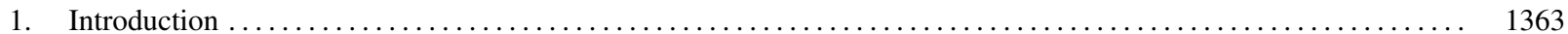

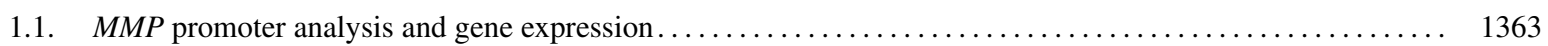

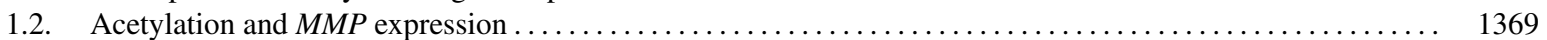

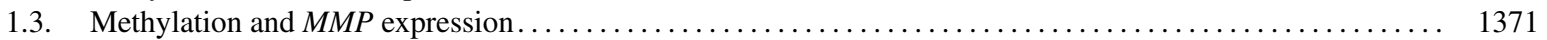

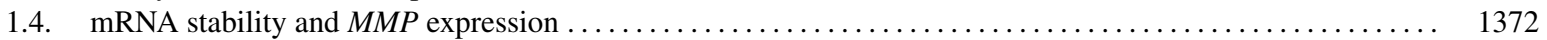

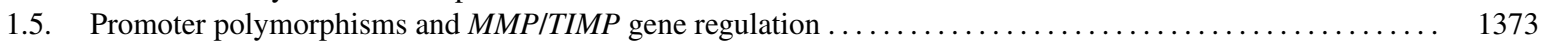

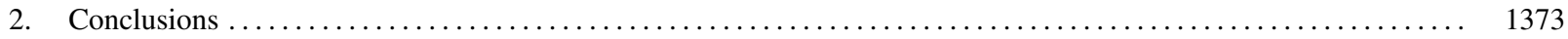

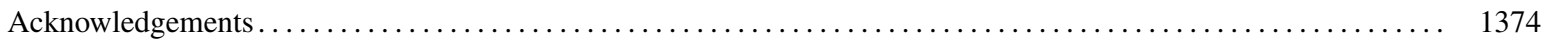

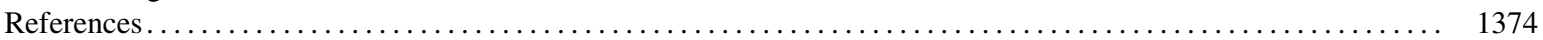

Abbreviations: AP-1, activator protein-1; AURE, AU-rich element; ECM, extracellular matrix; Egr1, early growth response 1; Ets, erythroblastosis twenty-six; HAT, histone acetyltransferase; HDAC, histone deacetylase; IE, immediate early; Lef, lymphoid enhancer factor; miR, microRNA; MMP, matrix metalloproteinase; NFкB, nuclear factor kappa B; PEA3, polyoma enhancer A3; PMA, phorbol myristate acetate; RARE, retinoic acid response element; Runx2, Runt-related transcription factor 2; Sp1, specificity protein 1; STAT, signal transducer and activator of transcription; Tcf, T-cell factor; TIMP, tissue inhibitor of metalloproteinases.

* Corresponding author.

E-mail address: i.clark@uea.ac.uk (I.M. Clark).

${ }^{1}$ Present address: Instituto de Salud Pública, Universidad Veracruzana, Xalapa, Veracruz, México. 


\section{Introduction}

The matrix metalloproteinases (MMPs) are a family of 23 enzymes in man. These enzymes were originally described as cleaving extracellular matrix (ECM) substrates with a predominant role in ECM homeostasis, but it is now clear that they have much wider functionality. Such functions include: opposing effects on angiogenesis via matrix degradation but also release of angiogenesis inhibitors (via digestion of e.g. plasminogen to generate angiostatin, and type XVIII collagen to generate endostatin); regulation of cell growth via cleavage of cell surface-bound growth factors and receptors, release of growth factors sequestered in the ECM or integrin signalling; regulation of apoptosis via release of death or survival factors; alteration of cell motility by revealing cryptic matrix signals, or cleavage of adhesion molecules; effects on the immune system and host defense; modulation of the bioactivity of chemokines (Cauwe, Van den Steen, \& Opdenakker, 2007).

Traditionally, the MMPs have been subdivided into collagenases, gelatinases, stromelysins, and membranetype MMPs, according to their substrate specificity, primary structure and cellular location. However, several more recently discovered enzymes do not fit easily into these classifications and alternatives based on domain structure, activation mechanism and cellular location have been suggested e.g. (Brinckerhoff \& Matrisian, 2002). The MMPs have a common domain structure with a signal peptide, a propeptide, a catalytic domain, a hinge region and, in the majority of cases, a C-terminal domain. The propeptide contains an invariant Cys residue (in all but MMP-23), which ligates the active site zinc ion to maintain latency; the catalytic domain contains a HEXGHXXGXXH zinc-binding sequence characteristic of the metzincin superfamily of proteinases, followed by an invariant methionine which is involved in a structural feature called the 'Met-turn'. In all family members except MMP-7(matrilysin-1), MMP-23 (CAMMP) and MMP-26 (matrilysin-2), a hinge region links to a haemopexin-like C-terminal domain which is thought to be involved in substrate specificity and binding of inhibitors. Individual MMPs contain variations on this theme e.g.: membrane-type (MT)-MMPs (MMPs 14-17, -24 and -25) have either a transmembrane domain and cytoplasmic tail at the C-terminus (MMP 14-16 and -24) or are GPI-anchored (MMP-17 and -25). In common with MMP-11, -21, -23 and -28, the MT-MMPs also contain a potential furin-cleavage site within the propeptide allowing activation prior to secretion. The gelatinases (MMP-2 and -9) have an insert of threefibronectin type II repeats in the catalytic domain and
MMP-9 also has a collagen-like sequence at one end of the catalytic domain.

A family of four specific inhibitors, the TIMPs, has been described (Baker, Edwards, \& Murphy, 2002). Whilst the ability of the four TIMPs to inhibit MMPs is largely promiscuous, a number of functional differences have been noted, e.g. TIMP-2, -3 and -4 , but not TIMP1 , are effective inhibitors of the MT-MMP subclass and MMP-19.

Control over MMP and/or TIMP activity in vivo occurs at different levels and involves factors such as regulation of gene expression, activation of zymogens and inhibition of active enzymes by specific inhibitors. Many MMPs and TIMPs are regulated at the level of transcription by a variety of growth factors, cytokines and chemokines e.g. (Yan \& Boyd, 2007).

\subsection{MMP promoter analysis and gene expression}

In addition to showing characteristic patterns of tissue- and developmental stage-specific patterns of expression (Nuttall et al., 2004), particular cell types display signal-dependent activation and repression of $M M P$ and TIMP gene transcription involving the mitogenactivated protein kinase (MAPK), nuclear factor-кB (NFKB) and Smad-dependent pathways (Borden \& Heller, 1997; Overall \& Lopez-Otin, 2002; Vincenti \& Brinckerhoff, 2002; Westermarck, Li, Kallunki, Han, \& Kahari, 2001). Most MMPs and TIMPs respond to stimuli at the transcriptional level with delayed kinetics over a timeframe of several hours and require ongoing translation (Sampieri et al., 2008). This suggests that they are components of genetic programmes such as the wound repair response, in which they are downstream targets of immediate-early (IE) response genes that are induced within minutes of cell stimulation and in the absence of new protein synthesis. Chief among these IE genes are the Fos and Jun genes that comprise activator protein-1 (AP-1) and at the level of the individual gene promoter, a promoter-proximal AP-1 site was the first cis-acting element to be implicated in the induction of $M M P 1$ expression (Angel et al., 1987). A number of $M M P$ promoters have now been at least partly characterized, revealing a variety of functional cis-acting elements (e.g. AP-1, PEA3, Sp1, Tcf/Lef-1, NFkB, RARE).

A recent review on MMP gene expression (Yan $\&$ Boyd, 2007) uses the basic promoter conformation to assign MMPs to one of three groups (i) those which contain TATA boxes at around -30 bp with AP1 sites around -70 bp (MMP1, MMP3, MMP7, MMP9, MMP10, MMP12, MMP13, MMP19 and MMP26); (ii) those which contain a TATA box, but no promoter- 
proximal AP-1 site $(M M P 8, M M P 11$ and $M M P 21)$; and (iii) those with no TATA box nor proximal AP-1 (MMP2, $M M P 14$ and $M M P 28)$.

A bioinformatic analysis across the $M M P$ family proves problematic since many known functional sites, including e.g. the promoter-proximal PEA3 site in $M M P 1$, are non-canonical. Furthermore, the transcription start point is unknown for many $M M P$ s and can only be inferred by examination of the longest known mRNA. However, using such methodology to analyse $1 \mathrm{~kb}$ of upstream sequence for each MMP and TIMP gene (Fig. 1) adds $M M P 20$ to group one (AP-1 and TATA containing); $M M P 15$ and $M M P 27$ to group two (TATA but no AP-1); and MMP16, MMP17, MMP23, MMP24 and $M M P 25$ to group three (no TATA, no AP-1). Of these, the assignment of the promoter region for $M M P 23$, $M M P 24$ and $M M P 25$ is most tenuous from the databases. As amongst most multi-gene families, the $M M P$ s can be co-regulated under a variety of stimuli, and the above classification is certainly useful, with e.g. many of the group 1 genes (TATA box and proximal AP-1 site) induced by interleukin-1 (IL-1), tumour necrosis factor alpha $(\mathrm{TNF} \alpha)$ or phorbol ester treatment in many cell types. However, it may disguise the inherent complexity which underlies the regulation of these genes and the subtlety by which differential regulation can be achieved.

Even accepting the promoter-proximal AP-1 site as a major mediator of regulation, specificity across genes or cell types remains possible. Firstly, the composition of the AP-1 complex itself may determine the response: early work indicated that c-Jun was able to induce $M M P 1$ minimal promoter constructs (in F9 cells which lack endogenous AP-1) whilst JunB was reported as a repressive factor in the absence of c-Fos, but an inducing factor in the presence of c-Fos (Chiu, Angel, \& Karin, 1989). The influence of the promoter-proximal AP-1 site may also change dependent on the construct under assay. Originally examined in the rabbit MMPl promoter, a second, non-canonical AP-1 site was identified at $-186 \mathrm{bp}$ which altered the response of the promoter to phorbol ester and removed some of the dependency on the promoter-proximal ( $-77 \mathrm{bp}$ ) AP-1 site. The AP1 complex at both sites contained c-Fos and JunD, but Fra-2 was only present at the -77 bp site (White \& Brinckerhoff, 1995). Other proteins may interact with the AP-1 site. Nucleolin was recently identified as such a protein, and chromatin immunoprecipitation (ChIP) shows it binding in the vicinity of the AP-1 site within the MMP13 promoter. Moreover, overexpression of nucleolin can repress transactivation of the $M M P 13$ promoter transiently transfected into HeLa cells (Samuel, Twizere, Beifuss, \& Bernstein, 2008).

Further complexity can be generated by the juxtaposition of transcription factor binding sites or indeed the presence of composite sites. Fra-1 alone was recently shown to be unable to transactivate the human MMP9 promoter in MCF7 cells. Promoter sequence analysis showed a STAT3 binding site in juxtaposition with the AP-1 site and indeed, the co-transfection of Fra-1 and Stat3C strongly transactivated the promoter. A complex of c-Jun/Fra-1 and Stat3 was identified on this region of the promoter (Song et al., 2008). In the MMP1 promoter, the proximal AP-1 site has been reported to be within a composite element with at least a peroxisome proliferator-activated receptor gamma (PPAR $\gamma)$ consensus whereby PPAR $\gamma$ and AP-1 bind the element in a mutually exclusive manner (Fahmi et al., 2002; Francois et al., 2004). Burrage, Huntington, Sporn, and Brinckerhoff (2007) extended this observation to show that the promoter-proximal AP-1 site in the $M M P 1$ and $M M P 13$ promoters overlap a degenerate direct repeat (DR)1 nuclear hormone response element with similar elements found more distally in other $M M P$ genes. Our own computer analysis in Fig. 1 shows such composite AP-1/RAR-RXR elements in the upstream $1 \mathrm{~kb}$ regions of at least $M M P 7, M M P 9$ and $M M P 19$ genes.

Interestingly, $M M P 11$ appears unique amongst characterised $M M P$ promoters in having a functional retinoic acid response element (DR1-RARE) in its proximal promoter mediating its induction by retinoic acid. Two upstream DR2-RAREs are also present and appear to contribute to basal expression from the gene promoter (Ludwig, Basset, \& Anglard, 2000). Bioinformatic analysis suggests several $M M P$ and TIMP promoters contain canonical retinoic acid or retinoid $\mathrm{X}$ receptor response elements within the upstream $1 \mathrm{~kb}$ region $(M M P 1$, MMP2, MMP7, MMP9, MMP11, MMP13, MMP14, MMP17, MMP19, MMP21, MMP23, MMP26, TIMP1, TIMP3 and TIMP4). Interestingly, these are almost all of the DR1 spacing, the most promiscuous of such sites,

Fig. 1. Bioinformatic analysis of $M M P$ and TIMP genes. The transcription start point (tsp) of each gene was either (i) taken from experimental evidence in the literature or (ii) inferred from the longest reported mRNA (Ensembl, http://www.ensembl.org/) with confirmation from other databases where possible (the latter method appeared particularly tenuous for MMP23, MMP24 and MMP25 genes). $1 \mathrm{~kb}$ of upstream (promoter) sequence was then analysed using MatInspector (Genomatix, http://www.genomatix.de/) to search for consensus sites for activator protein 1 (AP-1), activator protein 2 (AP-2), erythroblastosis twenty-six (Ets), polyoma enhancer element A3 (PEA3), GC box, nuclear factor kappa B (NFkB), retinoic acid response element (RAR/RXR), retinoid X response element (RXRE/RXR), Runt-related transcription factor 2 (Runx2), signal transducer and activator of transcription (STAT) and T-cell factor/lymphoid enhancer factor (Tcf/Lef). 
NFkb

(A)
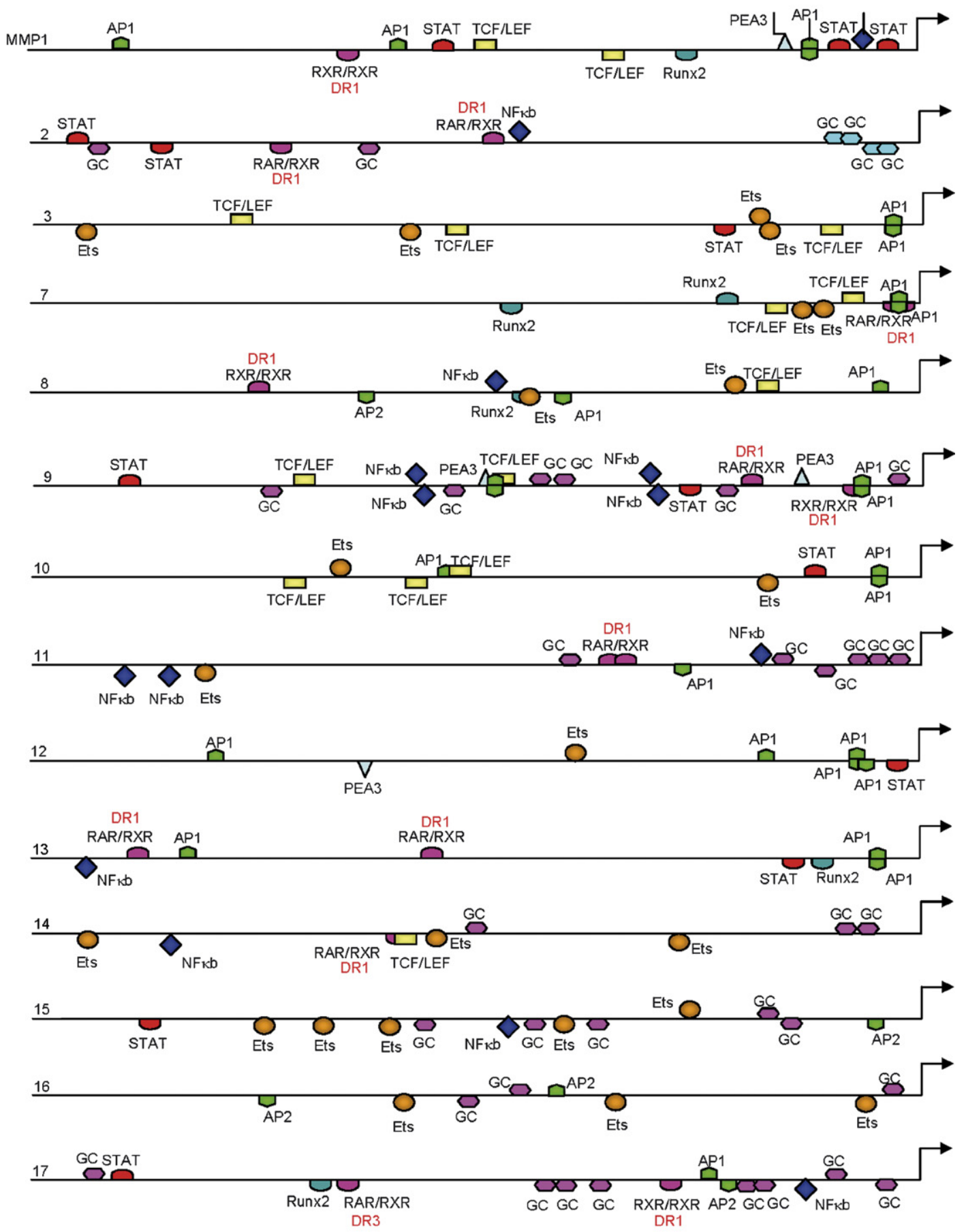
(B)
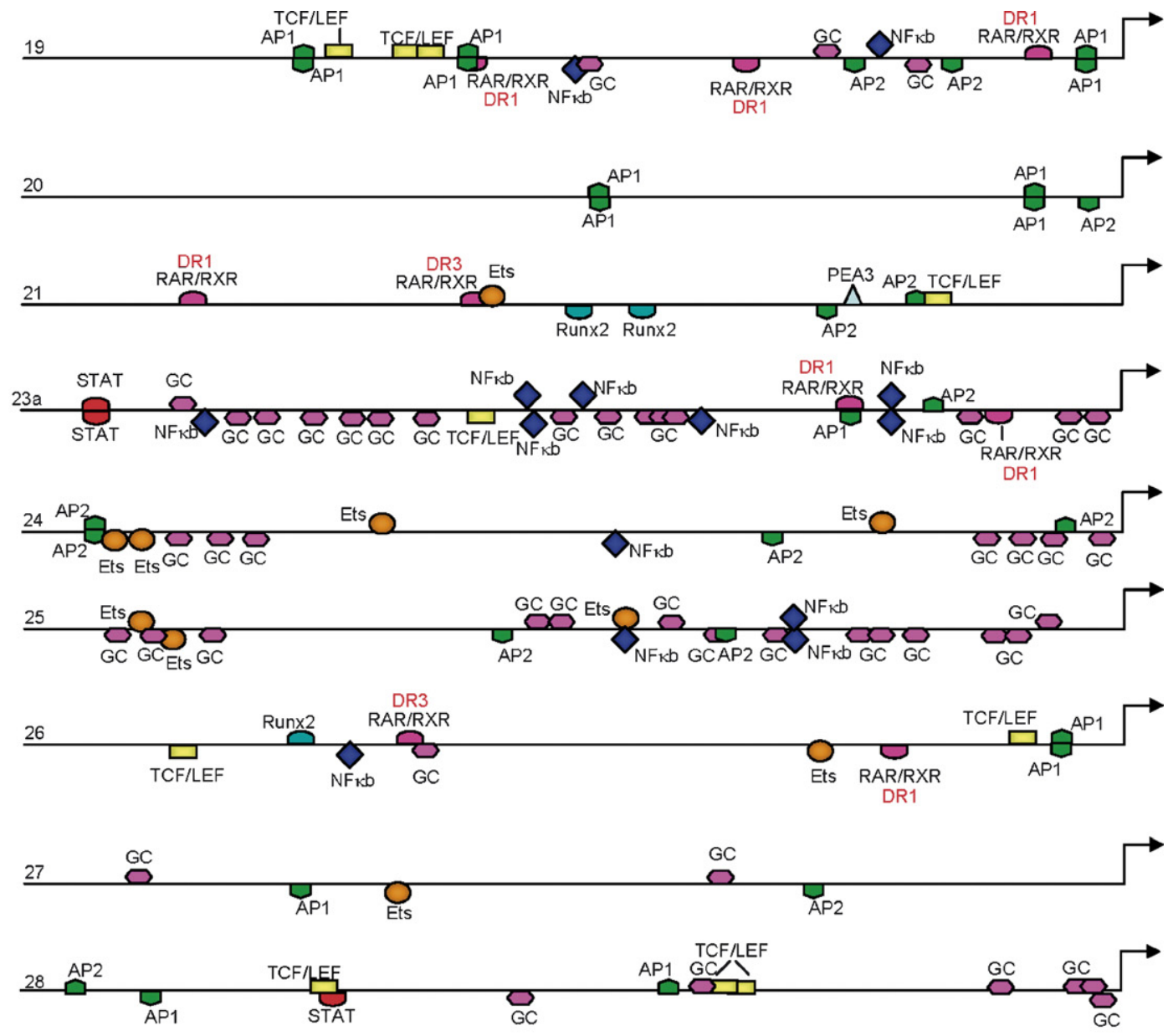

rive
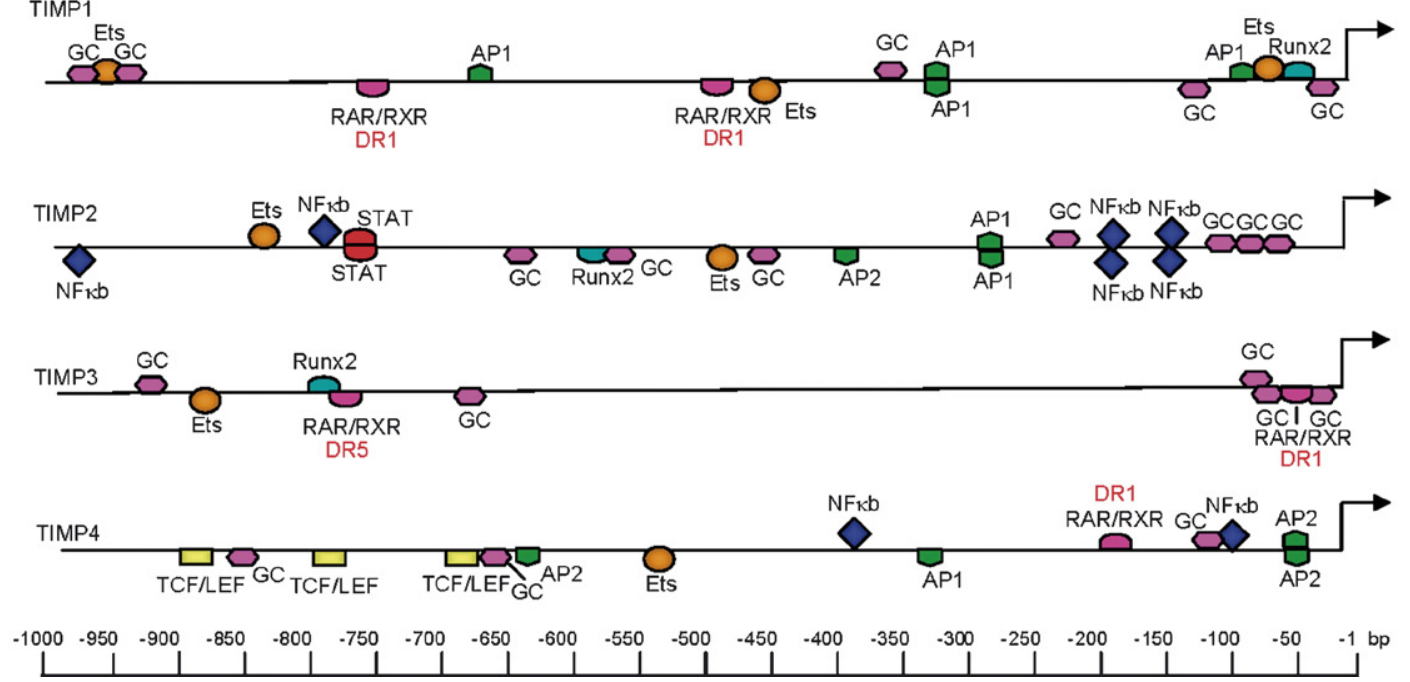

Fig. 1. (Continued). 
known to recruit at least $\mathrm{RAR} / \mathrm{RXR}, \mathrm{RXR} / \mathrm{RXR}$, and PPAR/RXR in vitro (Ijpenberg et al., 2004; Durand, Saunders, Leroy, Leid, \& Chambon, 1992; Mader, Leroy, Chen, \& Chambon, 1993; Mangelsdorf et al., 1991).

In many MMP promoters containing proximal AP-1 sites, a PEA3-binding consensus is found in close proximity upstream, and these sites act cooperatively. Again, since many of these sites are able to bind multiple Ets factors, they can mediate specificity. $M M P 1$ expression was shown to be differentially regulated by different structural classes of Ets factors e.g. Ets1, ErgB/Fli-1 and Pu1. Ets1 increased basal activity of $3.8 \mathrm{~kb} M M P 1$ promoter, whilst the others had no effect. Ets1 augmented transactivation by both c-Jun and JunB, ErgB augmented transactivation only via JunB, whilst Pul repressed induction by both c-Jun and JunB. As above, all of these effects were dependent on the promoter-proximal AP-1 site (Westermarck, Seth, \& Kahari, 1997).

Many $M M P$ s have multiple GC boxes in their proximal promoters which bind Sp1 and Sp3 and potentially other GC-binding proteins. The MMPs without other obvious promoter features are generally expressed in a more constitutive fashion e.g. $M M P 2$ and MMP14. Indeed, the promoter-proximal ( $-92 \mathrm{bp}$ ) Sp1 site in the MMP14 promoter is crucial in maintaining expression of this gene since its mutation reduces promoter activity by approximately $90 \%$ (Lohi, Lehti, Valtanen, Parks, \& Keski-Oja, 2000). Our bioinformatic analysis would add MMP15, MMP16, MMP17, MMP23, MMP24, MMP25, TIMP2 and possibly MMP27 and TIMP3 to this list. However, these genes are still clearly regulated and a number of promoter dissections show responsive sites outside of the GC boxes.

In astroglioma cells, an Sp1 site at $-91 /-84$ bp and an AP-2 site at $-61 /-53$ bp mediate activation of the $M M P 2$ gene by Sp1, Sp3 and AP-2 factors (Qin, Sun, \& Benveniste, 1999). MMP2 was also shown to be a target of p53 transactivation via a p53 site at $-1659 /-1622$ bp (Bian \& Sun, 1997; Yan, Wang, \& Boyd, 2002). Stat3 has also been linked with the induction of $M M P 2$ in cells from metastatic melanoma (Xie et al., 2004) via a consensus site in the promoter at $-617 /-610 \mathrm{bp}$. Other Stat 3 binding sites have been identified in the $M M P 2$ promoter within the upstream enhancer sequence (denoted RE-1 in the rat promoter) (En-Nia et al., 2002). Interestingly, in an ischaemia model, Fos and Jun proteins were shown to bind to a non-canonical AP-1 site in the $M M P 2$ promoter, with p53 binding to an adjacent enhancer site (RE-1) and NFAT-c2 binding within intron 1. Deletion of the former or substitution of the latter led to decreased expression in transgenic mice expressing beta-galactosidase from an $M M P 2$ promoter/intron
1 construct (Lee et al., 2005). The upstream (-1394 bp) AP-1 site had previously been described as important for the induction of $M M P 2$ expression by hypoxia in cardiac cells with binding of Fra1-JunB or FosB-JunB heterodimers (Bergman et al., 2003). This belies the idea that $M M P 2$ is constitutively produced and not regulated by AP-1 complexes.

Egr1, like Sp1 and Sp3, binds GC-rich sequences, and both specificity of binding to cognate sites and crosscompetition has also been demonstrated (Al-Sarraj, Day, \& Thiel, 2005)). Egr1 has been implicated in the regulation of e.g. MMP14 in cells cultured in three-dimensional matrices (Barbolina, Adley, Ariztia, Liu, \& Stack, 2007; Haas, Stitelman, Davis, Apte, \& Madri, 1999) or MMP14 and $M M P 2$ by cigarette smoke in lung fibroblasts (Ning et al., 2007).

In mesangial cells, MMP14 expression is regulated by proximal and overlapping Sp1- and Sp1/Egr1-binding sites as well as a more distal site for NFATc1 (AlfonsoJaume, Mahimkar, \& Lovett, 2004).

$\mathrm{NF \kappa \textrm {B }}$ is known to regulate many $M M P$ genes (Vincenti \& Brinckerhoff, 2007). An NFkB site was originally identified in the $M M P 9$ promoter $(\mathrm{He}, 1996)$ with a potential role in $\mathrm{TNF} \alpha$ induction of the gene. NFKB was also shown as essential for the synergistic induction of $M M P 9$ expression by growth factors and inflammatory cyokines (Bond, Fabunmi, Baker, \& Newby, 1998). MMPl is also regulated by NFkB, with a non-canonical site binding NFKB1 at -2886 bp in the rabbit promoter (Vincenti, Coon, \& Brinckerhoff, 1998). In other $M M P$ genes induced by NFKB, no functional NFKB sites have been identified: again, such sites could simply be non-canonical or some of these effects may be indirect. A number of $M M P$ and TIMP proximal promoters show canonical NFKB sites on sequence analysis $(M M P 1, M M P 2, M M P 8, M M P 9, M M P 11, M M P 13$, MMP14, MMP15, MMP17, MMP19, MMP23, MMP25, MMP26, TIMP2 and TIMP4).

$M M P 7$ was the first $M M P$ shown to be regulated by Wnt signalling being the target of beta-catenin regulation via Tcf/Lef-1. The human MMP7 promoter has two upstream Tcf/Lef- 1 binding sites at $-109 \mathrm{bp}$ and $-194 \mathrm{bp}$ which mediate transactivation of the promoter by beta-catenin (Gustavson, Crawford, Fingleton, \& Matrisian, 2004). Tcf/Lef-1 synergises with other factors, particularly those of the PEA3 family, to drive expression of $M M P 7$ in colorectal tumours (Crawford et al., 2001). MMP14 has also been identified as a target of beta-catenin signalling in colorectal cancers with a Tcf/Lef- 1 site at $-1169 /-1163$ bp mediating this effect (Takahashi, Tsunoda, Seiki, Nakamura, \& Furukawa, 2002). MMP26, a poorly expressed gene 
in most cell types, is also reported to have a Tcf motif in its promoter (Marchenko, Marchenko, Leng, \& Strongin, 2002). Bioinformatic analysis of the upstream $1 \mathrm{~kb}$ region reveals canonical Tcf/Lef sites in $M M P 1$, MMP3, MMP7, MMP8, MMP9, MMP10, MMP14, MMP19, MMP21, MMP23, MMP26, MMP27, MMP28 and TIMP4. Thus, these are common sequences within these genes, though most are not functionally verified.

The MMP13 gene is regulated in part by a promoterproximal Runx2 (aka Cbfa1, AML3) site which directs its expression in osteoblasts and hypertrophic chondrocytes (Jimenez et al., 1999; Porte et al., 1999). In stably transfected chondrocytic cell lines, IL-1 induces MMP13 expression via both promoter-proximal AP-1 and Runx2 sites (Mengshol, Vincenti, \& Brinckerhoff, 2001). Transgenic mice expressing beta-galatosidase from $-148 \mathrm{bp}$ of the rat MMP13 promoter, containing both the AP-1 and Runx 2 sites, display expression in bone, teeth and skin at levels that are elevated compared to transgenic lines in which these sites are mutated. This shows that the promoter-proximal AP-1 and Runx 2 sites in the MMP13 promoter are necessary and sufficient to direct expression in these tissues in vivo, though may not be sufficient to recapitulate all aspects of endogenous $M M P 13$ expression (Selvamurugan et al., 2006). Aside from MMP13, $M M P 9$ expression is also regulated by Runx2 via a promoter-proximal consensus and three non-canonical upstream Runx2 sequences (Pratap et al., 2005). This fits with a role for MMP-9 in endochondral ossification revealed by the growth plate phenotype of the $M M P 9$ null mouse (Ortega, Behonick, \& Werb, 2004). Interestingly, bioinformatic analysis shows canonical Runx 2 sites in the upstream $1 \mathrm{~kb}$ regions of $M M P 1, M M P 7, M M P 8$, MMP13, MMP17, MMP21, MMP26, TIMP1, TIMP2 and TIMP3 though, of course, these await functional analysis. Runx 2 may direct expression in hypertrophic chondrocytes and osteoblasts, but MMP13 and indeed most MMPs do not show true tissue specificity. MMP20 is the prime example, being expressed almost exclusively in tissues of the tooth. The bioinformatic analysis of $1 \mathrm{~kb}$ of upstream sequence (above) shows two canonical AP1 sites and this has been backed up experimentally in a recent paper which shows four potential AP-1 sites within $1.5 \mathrm{~kb}$ of promoter with three of them binding c-Jun (Zhang, Li, Chi, Chen, \& Denbesten, 2007).

Similar to the group $1 M M P$ s, TIMP1 has a promoterproximal AP-1 site (though non-canonical) with a neighbouring PEA3 site as major mediators of transcription. Logan, Garabedian, Campbell, and Werb (1996) demonstrated that the proteins binding to the AP-1 site at $-92 /-86$ bp may interact with those at the PEA-3 site at $-79 /-74$ bp to enhance transcription driven from the whole element. Interestingly, Phillips, Sharma, Leco, and Edwards (1999) showed that the TIMP1 AP-1 site was also able to bind a single-stranded DNA-binding protein whereas the (canonical) MMP1 AP-1 site did not. TIMP1 is both constitutively expressed and inducible and this may explain its lack of a TATA box, multiple transcription start points and GC boxes. A number of other consensus sites have also been shown to be functional within the promoter (e.g. upstream TIMP element- 1 which binds Runx 1 and Runx 2 proteins at $-62 /-52$ bp (Bertrand-Philippe et al., 2004; Trim et al., 2000), a hypoxia response element at $-27 /-23 \mathrm{bp}$, an Egr1 site at -33 bp (Aicher et al., 2003). The TIMPI gene differs from other TIMP family members in having a short first exon which is transcribed, but not translated, with the translation start site located on exon 2 . There is evidence that regulatory sequences exist within the first intron of the Timpl gene. Flenniken and Williams (1990) found that a construct containing around $1.3 \mathrm{~kb}$ of murine TIMP-1 $5^{\prime}$ flanking sequence, exon 1 and most of intron 1 linked to a lacZ reporter in transgenic mice was sufficient to reproduce the spatial and temporal expression of the Timpl gene in developing mouse embryos. In contrast to this, transgenic mice carrying lacZ linked to $2.7 \mathrm{~kb}$ of Timp1 $5^{\prime}$ flanking sequence, but lacking intron 1 , display a subset of the correct pattern of expression (e.g. appropriate expression in the developing vertebral column, and absence in the liver), but also inappropriate expression of the reporter in sites such as the spinal cord (D.R. Edwards, unpublished data). Thus, sequences within intron 1 are likely to repress Timpl gene expression and this was demonstrated in vitro by Dean, Young, Edwards, and Clark (2000) who showed at least Sp1, Sp3 and Ets-factor binding to a repressive cis-acting sequence in the intron.

The TIMP2 gene has a TATA box at around $-30 \mathrm{bp}$, though still displays multiple transcription start points. It contains several $\mathrm{Sp} 1$ sequences, characteristic of a housekeeping gene, two AP-2 sites, three PEA3 sites and an AP-1 site (at -281 bp) (Hammani et al., 1996). Interestingly, the AP-1 site does not lead to induction of the TIMP2 promoter by phorbol ester in the same way as does the more proximal site in the TIMP1 promoter. However, insertion of an AP-1 consensus at position $-71 \mathrm{bp}$ in the TIMP2 gene generates phorbol induction of the mutant. An Sp1 and Sp3-binding motif at $-107 /-98$ bp cooperates with an inverted CCAAT box, binding NF-Y, at 73/-69 bp for both basal expression from the TIMP2 promoter and its induction by cAMP (Zhong, Hammani, Bae, \& DeClerck, 2000).

The murine Timp3 gene has a TATA box and single transcription start point. The proximal (approximately 
$500 \mathrm{bp}$ ) promoter has three GC boxes, and more distally ( -600 to $-2000 \mathrm{bp}$ ) contains six AP-1 consensus sequences, two NFkB sites and two p53 sites (Sun et al., 1995). This structure is reflected in the activity of promoter fragments in transient transfection experiments where a $-2846 /+58$ bp construct is inducible by $\mathrm{TNF} \alpha$ or phorbol ester, but a $-491 /+23$ bp construct is not inducible by these factors. Interestingly, this group also found that Timp3 is poorly expressed in a number of neoplastic cell lines and that the promoter in these lines can be hypermethylated or hypomethylated. Treatment with a DNA methyl transferase inhibitor leads to reexpression of Timp 3 only in the line displaying promoter hypermethylation. Similarly, the human TIMP3 promoter displays a promoter-proximal GC-rich region which is capable of mediating basal expression, with regions further upstream mediating serum induction (Wick et al., 1995).

Amongst the TIMPs, TIMP4 displays tight tissue specificity, predominantly in the heart and brain (Leco et al., 1997). The TIMP4 promoter has no TATA box, but does contain an initiator sequence and the gene displays multiple transcription start points (Young et al., 2002). The proximal promoter contains an inverted CCAAT box and an Sp1 site. Mutation of the former causes an increase in reporter expression. More significantly, mutation of either the initiator sequence or the Sp1 site abolishes reporter expression completely.

\subsection{Acetylation and MMP expression}

Acetylation is a post-translational covalent protein modification that is strongly implicated in transcriptional regulation. Histones were the first proteins identified as showing variable acetylation status. Simplistically, acetylation weakens the histone:DNA interaction, allowing access to transcription factors and therefore generally associated with gene activation. This has been followed by a plethora of molecules ranging from structural proteins, intracellular signaling molecules, nuclear membrane receptors and transcription factors that have been shown to be acetylated. Acetylation, like phosphorylation, is a reversible modification with acetyl groups added by a family of histone acetyl transferase enzymes (HATs) and removed by histone deacetylases (HDACs). Inhibitors of the so-called classical HDACs (HDACs 1-11) are in development as cancer therapeutics as they have potent anti-proliferative and pro-apoptotic activities in cancer cells.

The role of acetylation in the expression of MMPs has been probed for a number of genes. An early report of acetylation impacting upon $M M P$ gene expression was by Pender, Quinn, Sanderson, and MacDonald (2000) working with human fetal mucosal mesenchymal cells. In this paper, HDAC inhibitors (HDACi) were shown to enhance IL-1 $\beta$ or TNF $\alpha$ induction of $M M P 3$ and to repress IL-1 $\beta$ or TNF $\alpha$ induction of $M M P 1$ and $M M P 9$ both at the mRNA and protein level. No effect of these HDACi was seen on unstimulated levels of any $M M P$ examined, and no effect was seen on MMP2 or TIMP1, neither of which was induced by IL- $1 \beta$ or TNF $\alpha$. From these data, it is likely that the effect of HDACi is on the signaling pathways induced by these proinflammatory cytokines, rather than on the $M M P$ genes themselves, though this is currently unknown. It is interesting that the same HDACi can lead to enhancement or repression of an induced $M M P$ (compare $M M P 3$ to $M M P 1$ and MMP9 above): this might suggest that there are differences in the pathways by which IL-1 or TNF $\alpha$ induce $M M P 3$ compared to $M M P 1$ and $M M P 9$ or that there are subtle differences in the impact of HDACi on e.g. NFкB that are gene specific.

Ailenberg and Silverman $(2002,2003)$ then described that HDAC inhibitors could repress $M M P 2$ gene expression at the mRNA level in NIH 3T3 cells. In this cell line, TSA did not alter expression of either MMP14 or TIMP2, factors known to be involved in proMMP-2 activation. $M M P 2$ expression in the human fibrosarcoma cell line HT1080 was much less sensitive to HDACi treatment, even at high concentrations. Similarly, Kaneko et al. (2004) demonstrate both reduced invasion through Matrigel, and reduced $M M P$ expression and activity, in response to HDACi. In human liver cancer cell lines, treatment with HDACi reduced activity of MMP-2 and MMP-9 and expression of MMP1. The expression of TIMP1 and TIMP2 was unaffected. Since the effect of HDACi on $M M P$ levels was similar to that of interferon$\alpha$, the authors speculate on cross-talk or commonality between the signalling pathways activated by these factors.

These papers do not dissect in detail the mechanism(s) by which HDACi impact upon $M M P$ gene expression in terms of the HDAC involved, nor in terms of the number of $M M P$ s affected by an HDACi. Yan, Wang, Toh, and Boyd (2003) showed that the metastasis-associated gene MTA1, a component of the NuRD repressor complex binds to $-650 /-450 \mathrm{bp}$ of the $M M P 9$ promoter, recruiting HDAC2 and decreasing histone acetylation and thereby gene expression. An HDAC independent mechanism involving the Mi-2 nucleosomal remodelling activity was also postulated. Martens, Verlaan, Kalkhoven, and Zantema (2003) considered the induction of the MMPl gene in T98G human glioblastoma cells by a combination of serum and phorbol ester. This 
combination gives a potent induction of $M M P 1$ expression at the mRNA level between $90 \mathrm{~min}$ and $2 \mathrm{~h}$ with a maximal induction at $4-6 \mathrm{~h}$. These authors used ChIP to identify factors recruited to the $M M P 1$ promoter in this system and examined the kinetics of histone modifications occurring with induction of the gene. Acetylation per se is insufficient to induce $M M P 1$ expression in these cells since HDACi had no effect on $M M P 1$ expression despite an increase in local $\mathrm{H} 3$ acetylation at the $M M P I$ promoter. It appears that upon activation with serum and phorbol ester, c-Jun, c-Fos, TBP, RNAPII and SET9 assemble on the $M M P 1$ promoter and histones at this location are dimethylated (and eventually trimethylated). p300 and RSK2 are then recruited which correlates with an increase in acetylation and phosphorylation of histones at the MMPl promoter. Finally, Swi/Snf, an ATP-dependent nucleosome remodeling complex is recruiting allowing initiation of transcription.

In a similarly detailed dissection of events at the promoter, Ma, Shah, Chang, and Benveniste (2004) examined PMA induction of the MMP9 gene in HeLa cells. Increased MMP9 mRNA is apparent by $2 \mathrm{~h}$ of PMA treatment and becomes maximal at $6 \mathrm{~h}$. An NFkB site, two AP-1 sites and an Sp1 site in the MMP9 promoter are all involved in induction. Micrococcal nuclease digestion demonstrates that the MMP9 promoter is in a regular nucleosomal array, and chromatin remodeling is necessary for $M M P 9$ transcription. This latter is elegantly proven by using a Brg1-deficient cell line (SW-13 cells); Brg1 is the ATPase subunit of the Swi/Snf complex. In these cells, MMP9 is not expressed on PMA stimulation, but transfection with Brg1 (but not an ATPase-null mutant) rescued responsiveness of MMP9 expression to PMA. ChIP experiments demonstrated recruitment of AP-1 factors, NFKB factors and $\mathrm{Sp} 1$ at appropriate time points, and modifications in histone acetylation, phosphorylation and methylation. MTA, a specific protein methyltransferase inhibitor, suppressed PMA-induced $M M P 9$ expression, whilst HDACi enhance PMA-induced MMP9 expression. These authors also demonstrated that both HDAC1- and HDAC3-containing complexes occupy the MMP9 promoter in unstimulated HeLa cells, but that these are removed upon stimulation with PMA. This was reinforced by the repressive effects of HDAC1 or HDAC3 (but not HDAC2 or HDAC4) on PMA-induced MMP9. Both of these papers (Ma, Shah et al., 2004; Martens et al., 2003) demonstrate a coordinated cascade of cell signaling, histone modifications, nucleosome remodeling and recruitment of transcription factors. This may be cell type, species, or stimulus-specific. Ma, Chang et al. (2004) also showed that Brg-1, the ATPase sub- unit of the Swi/SNF complex impacts upon MMP2 gene expression. Using SW-13 cells and adding back Brg-1 demonstrated that this factor is required for recruiting Sp1, AP-2 and RNA polymerase II to the $M M P 2$ promoter, with Sp3-binding decreased.

Using HDAC7 null mice, Chang et al. (2006) show that HDAC7 maintains vascular integrity in early embryogenesis via repression of MMP10. HDAC7 (or indeed HDAC5) binds to MEF2, shown to be a transcriptional activator of MMP10 to repress expression of the latter.

Young, Lakey et al. (2005) show that HDACi block IL-1/OSM-induced cartilage resorption in an explant model in a dose-dependent manner at the level of both proteoglycan and collagen release. This was accompanied by a reduction in activity and activation of procollagenases in the conditioned medium and a similar reduction in gelatinase activity. In cultured primary chondrocytes, HDACi repressed the IL-1/OSMinduction of collagenolytic MMPs (MMPI and 13). In SW1353 chondrosarcoma cells, the majority of metalloproteinase genes that were robustly induced by the IL-1/OSM combination, were then repressed by the HDACi; these were $M M P 1, M M P 3, M M P 7, M M P 8$, $M M P 10, M M P 12$ and $M M P 13$. The basal expression of three metalloproteinase genes (MMP17, MMP23 and $M M P 28)$ was also induced by HDACi. These data suggest that HDACi impact upon IL-1/OSM signaling to repress induced levels of metalloproteinases and that the basal expression of a number of metalloproteinases is responsive to HDACi. There is no overlap between these groups, which may point to mechanisms/pathways by which groups of genes are coexpressed in these enzyme families.

At the simplest level, acetylation of histones at a gene promoter may increase access to cis-acting sequences by their cognate transcription factors. However, acetylation and deacetylation of signaling pathway components and transcription factors themselves makes the situation complex. This complexity is undoubtedly increased by cell specific differences in some of these events.

Young, Billingham, Sampieri, Edwards, and Clark (2005) detail the differential effects of HDACi on the TIMPI gene dependent on the stimulus used to induce the gene. HDACi enhance PMA-induced TIMPI expression but repress TGF $\beta$-induced TIMP1 expression. Interestingly, the dose (of HDACi)-response curves for these two effects are markedly different. This strongly suggests that different HDACs are the target of HDACi in each case. Furthermore, the effect of HDACi on the endogenous TIMP1 gene can be reiterated at the level of transient transfection of promoter-reporter constructs. 
This perhaps suggests that their effects are more likely mediated by acetylation of signaling molecules or transcription factors rather than histones.

As discussed above, many inducible $M M P$ genes contain promoter-proximal AP-1 sites that are key features of their inducibility. In order for c-Jun to activate target gene transcription, it requires phosphorylation by the Jun-N-terminal kinase (JNK) at serines 63/73 and threonines 91/93. An 'activation by de-repression' model has been proposed for the mechanism by which phosphorylation activates c-Jun. Thus, c-Jun phosphorylation mediates dissociation of an inhibitory complex which is associated with HDAC3. Subsequent to this dissociation, c-Jun can go on to activate target gene expression whether or not it is phosphorylated. c-Jun can also be activated by an increase in cellular levels of c-Jun protein thereby titrating out limiting components of the repressor complex (Weiss et al., 2003). c-Jun can itself be the target of acetylation, at least under specific circumstances. The MMP1 promoter can be activated by c-Jun, and repressed by the adenoviral E1A protein. p300 binds to E1A and repression of c-Jun induction of $M M P 1$ expression is dependent upon acetylation of c-Jun at Lys271 (Vries et al., 2001) A further report also demonstrates that HDACi can suppress the expression of $c$-jun and therefore the level of c-Jun protein. This in turn leads to decreased binding of c-Jun to promoters of cognate genes such as $C O X 2$ or $M M P 1$ and therefore HDACi suppress the phorbol ester-induced expression of these genes (Yamaguchi, Lantowski, Dannenberg, \& Subbaramaiah, 2005). Data from the Clark laboratory align with this where TSA represses PMA-induced $M M P 1$ expression in a number of cell lines (MRC5, HeLa, SW1353) (unpublished).

A recent paper suggests that Stats undergo acetylation at Lys 685 and that this is essential for their dimerisation and nuclear translocation (Yuan, Guan, Chatterjee, \& Chin, 2005). In this case, the action of HDACi would increase acetylation and therefore potentiate Stat signaling. Whilst there are instances of this in the literature (e.g. the IL-4 induction of the 15-lipoxygenase1 gene, (42), more recent data appear to show the opposite effect in the majority of cases. Thus, HDACi have revealed an essential role for HDACs in the transcription of interferon-responsive genes (Genin, Morin, \& Civas, 2003; Nusinzon \& Horvath, 2003; Rascle, Johnston, \& Amati, 2003; Sakamoto, Potla, \& Larner, 2004) since such inhibitors repress IFN-stimulated gene expression.

As above, several $M M P$ genes respond to proinflammtory stimuli, at least in part, via the NFкB pathway. Acetylation can impact upon this signaling pathway at a number of levels. Firstly, NFkB interacts with a number of HATs (including CBP, p300, P/CAF) and HDACs to impact upon gene expression. More specifically, HDACi delay postinduction repression of $\mathrm{NF \kappa B}$ via prolonged activity of IKK and therefore persistent degradation of Iк $\mathrm{B} \alpha$ and delayed build up of cytoplasmic IкB $\alpha$ after an inflammatory stimulus. The mechanism of this enhanced IKK activity is unknown (Quivy \& Van Lint, 2004). Further, both p50 and p65, the most common components of the NFKB dimer can be acetylated at multiple lysine residues. p50 acetylation increases DNA-binding affinity and this correlates with induction of genes such as COX2 and iNOS (Quivy \& Van Lint, 2004). There are opposing views of the outcome of p65 acetylation. Kiernan et al. (2003) show that p65 acetylation reduces DNAbinding affinity and enhances $\mathrm{NF \kappa B}$ removal from the

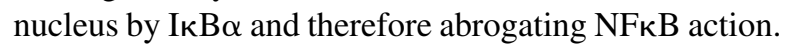
Chen, Fischle, Verdin, and Greene (2001) and Chen, Mu, and Greene (2002) show that p65 acetylation diminishes binding to $\mathrm{I} \kappa \mathrm{B} \alpha$, allowing increased nuclear translocation of NFKB and potentiation of signaling. They further show that HDAC3 deacetylates p65 to abrogate signaling and this fits with the ability of HDACi to potentiate or prolong NFKB signaling induced by TNF $\alpha$.

A number of other transcription factors relevant to $M M P$ gene expression are also subject to regulation at the level of acetylation, including Sp1 and Sp3 and Ets family members (Ammanamanchi, Freeman, \& Brattain, 2003; Braun, Koop, Ertmer, Nacht, \& Suske, 2001; Czuwara-Ladykowska, Sementchenko, Watson, \& Trojanowska, 2002; Yang \& Sharrocks, 2004).

\subsection{Methylation and MMP expression}

In multicellular eukaryotes, DNA methylation is restricted to cytosine bases with a number of known DNA methyltransferases acting to methylate cytosines within $\mathrm{CpG}$ dinucleotides. Methylation is usually associated with a repressive chromatin state and inhibition of gene expression. Methylation may block the binding of transcriptional activators and/or methyl binding proteins may recruit transcriptional repressors including HDACs (Klose \& Bird, 2006).

In lymphoma cells an inverse correlation was noted between $M M P 9$ promoter methylation and the level of MMP9 expression (Chicoine et al., 2002). This was confirmed functionally with in vitro experiments. Similarly, a colon cancer cell line in which the DNA methyltransferases Dnmt-1 and Dnmt-3b were knocked out, show increased expression of $M M P 3$ (but not $M M P 1$ or $M M P 2)$. Treatment of wildtype cells with DNA methyl transferase inhibitors recapitulated this effect whilst in 
vitro methylation of the MMP3 promoter suppressed its activity (Couillard, Demers, Lavoie, \& St-Pierre, 2006). The induction of $M M P 3$ by hypomethylation was also shown to be cell-specific since in a lymphoma cell line the methylase inhibitors showed no induction of MMP3, but induction of MMP10. A further group (Shukeir, Pakneshan, Chen, Szyf, \& Rabbani, 2006) used the invasive prostate cancer cell line PC-3, treated with a methyl donor or antisense against methyl DNA-binding domain protein 2. Both treatments led to the repression of $M M P 2$ expression and decrease in tumour volume in vivo. Bisulfite sequencing was used to show that the $5^{\prime}$ region of the $M M P 2$ gene was methylated in response to the above treatments.

In osteoarthritis, chondrocytes expressed increased levels of $M M P 3, M M P 9$ and $M M P 13$. Methylated $\mathrm{CpG}$ sites were decreased across the promoters of these genes with specific sites showing significantly higher demethylation in each gene (Roach et al., 2005).

As mentioned above for TIMP3, a number of studies demonstrate that silencing of TIMP genes via promoter methylation as a feature of cancer cells e.g. (Yuan, Jefferson, Popescu, \& Reynolds, 2004). The TIMP1 gene is on the $\mathrm{X}$ chromosome and is thus subject to $\mathrm{X}$ chromosome inactivation in females. Not all genes on the inactive $\mathrm{X}$ chromosome are completely silenced and TIMP1 is reported to display variable inactivation via both methylation status and changes in chromatin structure (Anderson \& Brown, 2005).

It is interesting to note that whilst the $M M P$ genes are distributed widely among the human chromosomes, there is a cluster at $11 \mathrm{q} 22$ containing nine gene $(M M P 1$, MMP3, MMP7, MMP8, MMP10, MMP12, MMP13, $M M P 20$ and $M M P 27)$. The regulation of these genes may require particular epigenetic features (chromatin marks and/or structure) that are currently not understood.

\section{4. mRNA stability and MMP expression}

At the post-transcriptional level, gene expression can be regulated via the stability of mRNA in the cytoplasm. This is mediated via a variety of trans-acting factors including both RNA-binding proteins and microRNAs (miR) that interact with cis-elements located at many sites in the mRNA. The most commonly described cis element is the AUUUA sequence which is often found in multiple copies within the $3^{\prime}$ UTR of mRNAs. Binding of protein factors to these elements can stabilize (e.g. HuR) or destabilise (e.g. AUF1) such mRNAs (Garneau, Wilusz, \& Wilusz, 2007).

$M M P$ and TIMP expression may be regulated (or perhaps fine-tuned) at this level. Vincenti, White, Schroen,
Benbow, and Brinckerhoff (1996) showed that the induction of $M M P 1$ by IL-1 $\beta$ in rabbit synovial fibroblasts required both transcriptional and post-transcriptional components. In terms of the latter, the $3^{\prime}$ UTR of the rabbit gene was able to destabilize a constitutively expressed reporter. IL-1 treatment stabilized a cloned human $M M P 1$ transcript, as did mutation of ATTTA motifs in the $3^{\prime}$ UTR. This demonstrates that, aside from transcriptional activation, IL-1 increases $M M P 1$ steady state mRNA by countering the destabilizing effects of the $3^{\prime}$ UTR.

Similarly, cortisol induces MMP13 steady state mRNA in osteoblasts by stabilizing transcripts (Rydziel, Delany, \& Canalis, 2004). Cortisol was shown to increase protein binding to AU-rich elements in the MMP13 $3^{\prime}$ UTR. Studies using transgene reporters show that the MMP13 3'UTR stabilizes a c-fos mRNA, with cortisol further increasing mRNA stability in this system. Mutation of the MMP133'UTR AU-rich elements destabilizes c-fos transcripts compared to wild-type and blocks the effects of cortisol. Both vinculin and far upstream element (FUSE) binding protein 2 were shown to interact with the MMP13 $3^{\prime} \mathrm{UTR}$ and knockdown of these proteins impacted upon MMP13 mRNA decay.

MMP9 expression can also be controlled at the level of mRNA stability. In mesangial cells, the ATP ana$\log$ ATP $\gamma \mathrm{S}$ potentiates the ability of IL-1beta to induce steady-state $M M P 9$ mRNA. This effect is via three AUrich elements in the $3^{\prime}$ UTR of the $M M P 9$ gene which are constitutively bound in these cells by the RNA stabilizing factor HuR. The binding of HuR-containing complexes to these sites was increased by ATP $\gamma \mathrm{S}$, and the ATP-dependent effect on MMP9 UTR was abolished by mutation in the three AURE (though this had no effect on IL-1 induction itself) (Huwiler et al., 2003). The same group identified a similar mechanism for the ability of nitric oxide to reduce $M M P 9$ steady state mRNA. Recombinant HuR stabilized, whilst antiHuR antibody destabilized, the $M M P 9$ mRNA. Nitric oxide was shown to attenuate the expression of HuR and its binding to the MMP9 $3^{\prime} \mathrm{UTR}$ AU-rich elements via a cGMP-dependent mechanism (Akool el et al., 2003).

The TIMP3 $3^{\prime}$ UTR was recently identified as a target for HuR binding in a screen of such mRNAs (Lal et al., 2004). There are other reports of regulation of TIMP mRNA stability, e.g. in astrocytes, regulation of mRNA decay is reported to contribute to the downregulation of TIMP1 expression by IL-1 (Gardner et al., 2006), however, molecular detail is yet to be described.

Micro RNAs (miRs) are small 21-25 nucleotide RNAs that negatively regulate gene expression at the 
post-transcriptional level, causing either inhibition of translation or mRNA degradation. The numbers of identified miRs are growing rapidly, and there is speculation that as much as $30 \%$ of the human genome may be subject to regulation in this fashion (Lewis, Shih, JonesRhoades, Bartel, \& Burge, 2003). In cancer, miR profiles both identify the tissue of origin of tumours ( $\mathrm{Lu}$ et al., 2005), and are prognostic (Volinia et al., 2006). Individual miRs function as tumour suppressor genes by regulating the expression of proto-oncogenes such as Ras, or conversely examples such as miR-21 act as oncogenes when over-expressed, by down-regulating expression of pro-apoptotic genes (Chan, Krichevsky, \& Kosik, 2005). To date little is known of the role of miRs in regulation of cellular protease networks, but bioinformatic analysis has indicated that several $M M P$ and TIMP genes contain miR binding sites in their $3^{\prime} \mathrm{UTRs}$, including MMP2 (miR-29), MMP14 (miR-24, miR-26 and miR-181), TIMP2 (miR-30) and TIMP3 (miR-21, $m i R-1 / 206$ and $m i R-181$ ) (Dalmay \& Edwards, 2006). Since TIMP3 is considered to be a tumour suppressor function that is often down-regulated in cancers, its possible regulation by miRs is intriguing and merits further investigation.

\subsection{Promoter polymorphisms and MMP/TIMP gene regulation}

Single nucleotide polymorphisms are variations in DNA sequence common in the population which may exist anywhere across a gene. Within gene promoters, such differences in genotype may alter promoter function and thus gene regulation.

The first single nucleotide polymorphism to be described in an $M M P$ gene promoter was the 5A/6A SNP at -1612 bp in MMP3 (Ye et al., 1996). This SNP is within an interleukin-1 responsive element, with the $5 \mathrm{~A}$ allele driving greater expression in reporter assays. The transcription factor ZBP89/ZNF148 and p65 containing dimers of NFKB all bind with similar affinity to either $5 \mathrm{~A}$ or $6 \mathrm{~A}$ allele, though $\mathrm{p} 50$ homodimers binds more effectively to the latter. This is hypothesized to act as a transcriptional repressor by competing for other, activating, NFKB variants, though this has not been experimentally verified. This SNP associates with a number of cardiovascular conditions (Ye, 2006).

Rutter et al. (1998) reported a SNP in the promoter of the MMP1 gene at -1607 bp where an additional $\mathrm{G}$ residue creates an Ets binding site ( $5^{\prime}$ GGAT3' compared to $5^{\prime} \mathrm{GAT}^{\prime}$ ) adjacent to an AP-1 site at $-1602 \mathrm{bp}$. The $2 \mathrm{G}$ allele leads to higher levels of $M M P 1$ expression (e.g. in A2058 melanoma cells) with evidence point- ing to at least Fra-1 preferentially targeting transcription from this allele (Tower, Coon, Belguise, Chalbos, \& Brinckerhoff, 2003). A variety of reports show association with either favourable (e.g. (Hettiaratchi et al., 2007)) or unfavourable e.g. (Cao \& Li, 2006; Zhu, Spitz, Lei, Mills, \& Wu, 2001) facets of cancer, though it should be noted that a number of studies show no association e.g. (Fong et al., 2004). Other pathologies have also been examined, with e.g. Malik, Jury, Bayat, Ollier, and Kay (2007) reporting that the $2 \mathrm{G} M M P 1$ genotype was highly associated with aseptic loosening after total hip replacement compared to controls.

A C to T SNP at $-1562 \mathrm{bp}$ in the $M M P 9$ gene impacts upon transcription of the gene. An unidentified nuclear protein has higher affinity to the $\mathrm{T}$-allele than the $\mathrm{C}$-allele with the former exhibiting higher activity in reporter assays (Zhang et al., 1999). Studies in tissues from individuals suggest that this is replicated in vivo. The $M M P 9$ promoter also contains a CA repeat region at approx $-131 /-90$ bp which can vary between 14 and 23 repeats. Shorter repeat regions display reduced $M M P 9$ promoter activity, and this also correlates with expression of the gene both lung and oesophageal cancer cell lines (Huang et al., 2003; Shimajiri et al., 1999).

Functional SNPs in the $M M P 2$ promoter include a $-1575 \mathrm{bp} G$ to $A$ polymorphism altering binding of oestrogen receptor (Harendza et al., 2003) and a $-1306 \mathrm{bp} \mathrm{C}$ to T polymorphism altering binding of Sp1 (Price, Greaves, \& Watkins, 2001). Other SNPs have been described in the promoters of MMP7, MMP12 and MMP13 (Ye, 2006).

Similarly to the $M M P 2$ SNP described above, a -418 bp $\mathrm{G}$ to $\mathrm{C}$ polymorphism abolishes an Sp1 site in the TIMP2 promoter and this shows association with COPD (Hirano et al., 2001) and some association with breast cancer risk (Zhou et al., 2004). Two promoter variants in the TIMP3 gene, a -915 bp A to $\mathrm{G}$ and $-1296 \mathrm{bp}$ $\mathrm{T}$ to $\mathrm{C}$ polymorphism, appear to contribute to susceptibility to the chronic lung disorder pigeon breeders disease (Hill et al., 2004).

\section{Conclusions}

Unsurprisingly the regulation of the MMP and TIMP gene families is complex. These genes are regulated across development, in adult physiology and in disease. In many situations, a number of genes within these families are being transcribed simultaneously, though such subsets will differ depending on e.g. cell type and stimulus. Hence, the combinatorial control of gene expression at the promoter level can be coupled with epigenetic control at the level of chromatin structure and post- 
transcriptional mechanisms, to give sufficient subtlety to $M M P$ and TIMP gene regulation. Our understanding of these processes at the level of individual genes is reasonably detailed in specific instances, however the future challenge is to understand the regulation of the families at a more global level. As high-throughput methodologies are developed to study e.g. gene expression, structure and transcription factor binding and activity, coupled with appropriate in vivo promoter dissection, this will eventually yield.

\section{Acknowledgements}

T.E.S. is funded by the Dunhill Medical Trust; D.R.E. would like to acknowledge the support of the European Union Framework 6 Cancerdegradome project (LSHCCT-2003-503297).

\section{References}

Aicher, W. K., Alexander, D., Haas, C., Kuchen, S., Pagenstecher, A., Gay, S., et al. (2003). Transcription factor early growth response 1 activity up-regulates expression of tissue inhibitor of metalloproteinases 1 in human synovial fibroblasts. Arthritis Rheum., 48, 348-359.

Ailenberg, M., \& Silverman, M. (2002). Trichostatin A-histone deacetylase inhibitor with clinical therapeutic potential-is also a selective and potent inhibitor of gelatinase A expression. Biochem. Biophys. Res. Commun., 298, 110-115.

Ailenberg, M., \& Silverman, M. (2003). Differential effects of trichostatin A on gelatinase A expression in 3 T3 fibroblasts and HT-1080 fibrosarcoma cells: Implications for use of TSA in cancer therapy. Biochem. Biophys. Res. Commun., 302, 181-185.

Akool el, S., Kleinert, H., Hamada, F. M., Abdelwahab, M. H., Forstermann, U., Pfeilschifter, J., et al. (2003). Nitric oxide increases the decay of matrix metalloproteinase 9 mRNA by inhibiting the expression of mRNA-stabilizing factor HuR. Mol. Cell. Biol., 23, 4901-4916.

Alfonso-Jaume, M. A., Mahimkar, R., \& Lovett, D. H. (2004). Cooperative interactions between NFAT (nuclear factor of activated $\mathrm{T}$ cells) $\mathrm{c} 1$ and the zinc finger transcription factors $\mathrm{Sp} 1 / \mathrm{Sp} 3$ and Egr-1 regulate MT1-MMP (membrane type 1 matrix metalloproteinase) transcription by glomerular mesangial cells. Biochem. J., 380, 735-747.

Al-Sarraj, A., Day, R. M., \& Thiel, G. (2005). Specificity of transcriptional regulation by the zinc finger transcription factors $\mathrm{Sp} 1, \mathrm{Sp} 3$, and Egr-1. J. Cell. Biochem., 94, 153-167.

Ammanamanchi, S., Freeman, J. W., \& Brattain, M. G. (2003). Acetylated sp3 is a transcriptional activator. J. Biol. Chem., 278, 35775-35780.

Anderson, C. L., \& Brown, C. J. (2005). Epigenetic predisposition to expression of TIMP1 from the human inactive $\mathrm{X}$ chromosome. BMC Genet., 6, 48.

Angel, P., Baumann, I., Stein, B., Delius, H., Rahmsdorf, H. J., \& Herrlich, P. (1987). 12-O-tetradecanoyl-phorbol-13-acetate induction of the human collagenase gene is mediated by an inducible enhancer element located in the $5^{\prime}$-flanking region. Mol. Cell. Biol., 7, 2256-2266.
Baker, A. H., Edwards, D. R., \& Murphy, G. (2002). Metalloproteinase inhibitors: Biological actions and therapeutic opportunities. J. Cell. Sci., 115, 3719-3727.

Barbolina, M. V., Adley, B. P., Ariztia, E. V., Liu, Y., \& Stack, M. S. (2007). Microenvironmental regulation of membrane type 1 matrix metalloproteinase activity in ovarian carcinoma cells via collageninduced EGR1 expression. J. Biol. Chem., 282, 4924-4931.

Bergman, M. R., Cheng, S., Honbo, N., Piacentini, L., Karliner, J. S., \& Lovett, D. H. (2003). A functional activating protein 1 (AP-1) site regulates matrix metalloproteinase 2 (MMP-2) transcription by cardiac cells through interactions with JunB-Fra1 and JunB-FosB heterodimers. Biochem. J., 369, 485-496.

Bertrand-Philippe, M., Ruddell, R. G., Arthur, M. J., Thomas, J., Mungalsingh, N., \& Mann, D. A. (2004). Regulation of tissue inhibitor of metalloproteinase 1 gene transcription by RUNX1 and RUNX2. J. Biol. Chem., 279, 24530-24539.

Bian, J., \& Sun, Y. (1997). Transcriptional activation by p53 of the human type IV collagenase (gelatinase A or matrix metalloproteinase 2) promoter. Mol. Cell. Biol., 17, 6330-6338.

Bond, M., Fabunmi, R. P., Baker, A. H., \& Newby, A. C. (1998). Synergistic upregulation of metalloproteinase- 9 by growth factors and inflammatory cytokines: An absolute requirement for transcription factor NF-kappa B. FEBS Lett., 435, 29-34.

Borden, P., \& Heller, R. A. (1997). Transcriptional control of matrix metalloproteinases and the tissue inhibitors of matrix metalloproteinases. Crit. Rev. Eukaryot. Gene Exp., 7, 159-178.

Braun, H., Koop, R., Ertmer, A., Nacht, S., \& Suske, G. (2001). Transcription factor $\mathrm{Sp} 3$ is regulated by acetylation. Nucleic Acids Res., 29, 4994-5000.

Brinckerhoff, C. E., \& Matrisian, L. M. (2002). Matrix metalloproteinases: A tail of a frog that became a prince. Nat. Rev. Mol. Cell. Biol., 3, 207-214.

Burrage, P. S., Huntington, J. T., Sporn, M. B., \& Brinckerhoff, C. E. (2007). Regulation of matrix metalloproteinase gene expression by a retinoid X receptor-specific ligand. Arthritis Rheum., 56, 892-904.

Cao, Z. G., \& Li, C. Z. (2006). A single nucleotide polymorphism in the matrix metalloproteinase-1 promoter enhances oral squamous cell carcinoma susceptibility in a Chinese population. Oral Oncol., $42,32-38$

Cauwe, B., Van den Steen, P. E., \& Opdenakker, G. (2007). The biochemical, biological, and pathological kaleidoscope of cell surface substrates processed by matrix metalloproteinases. Crit. Rev. Biochem. Mol. Biol., 42, 113-185.

Chan, J. A., Krichevsky, A. M., \& Kosik, K. S. (2005). MicroRNA21 is an antiapoptotic factor in human glioblastoma cells. Cancer Res., 65, 6029-6033.

Chang, H. M., Paulson, M., Holko, M., Rice, C. M., Williams, B. R., Marie, I., et al. (2004). Induction of interferon-stimulated gene expression and antiviral responses require protein deacetylase activity. Proc. Natl. Acad. Sci. U.S.A., 101, 9578-9583.

Chang, S., Young, B. D., Li, S., Qi, X., Richardson, J. A., \& Olson, E. N. (2006). Histone deacetylase 7 maintains vascular integrity by repressing matrix metalloproteinase 10. Cell, 126, 321-334.

Chen, L., Fischle, W., Verdin, E., \& Greene, W. C. (2001). Duration of nuclear NF-kappaB action regulated by reversible acetylation. Science, 293, 1653-1657.

Chen, L. F., Mu, Y., \& Greene, W. C. (2002). Acetylation of RelA at discrete sites regulates distinct nuclear functions of NF-kappaB. EMBO J., 21, 6539-6548.

Chicoine, E., Esteve, P. O., Robledo, O., Van Themsche, C., Potworowski, E. F., \& St-Pierre, Y. (2002). Evidence for the role of 
promoter methylation in the regulation of MMP-9 gene expression. Biochem. Biophys. Res. Commun., 297, 765-772.

Chiu, R., Angel, P., \& Karin, M. (1989). Jun-B differs in its biological properties from, and is a negative regulator of, c-Jun. Cell, 59, 979-986.

Couillard, J., Demers, M., Lavoie, G., \& St-Pierre, Y. (2006). The role of DNA hypomethylation in the control of stromelysin gene expression. Biochem. Biophys. Res. Commun., 342, 12331239.

Crawford, H. C., Fingleton, B., Gustavson, M. D., Kurpios, N., Wagenaar, R. A., Hassell, J. A., et al. (2001). The PEA3 subfamily of Ets transcription factors synergizes with beta-catenin-LEF-1 to activate matrilysin transcription in intestinal tumors. Mol. Cell. Biol., $21,1370-1383$.

Czuwara-Ladykowska, J., Sementchenko, V. I., Watson, D. K., \& Trojanowska, M. (2002). Ets 1 is an effector of the transforming growth factor beta (TGF-beta) signaling pathway and an antagonist of the profibrotic effects of TGF-beta. J. Biol. Chem., 277, 2039920408.

Dalmay, T., \& Edwards, D. R. (2006). MicroRNAs and the hallmarks of cancer. Oncogene, 25, 6170-6175.

Dean, G., Young, D. A., Edwards, D. R., \& Clark, I. M. (2000). The human tissue inhibitor of metalloproteinases (TIMP)-1 gene contains repressive elements within the promoter and intron 1. J. Biol. Chem., 275, 32664-32671.

Durand, B., Saunders, M., Leroy, P., Leid, M., \& Chambon, P. (1992). All-trans and 9-cis retinoic acid induction of CRABPII transcription is mediated by RAR-RXR heterodimers bound to DR1 and DR2 repeated motifs. Cell, 71, 73-85.

En-Nia, A., Reisdorff, J., Stefanidis, I., Floege, J., Heinrich, P. C., \& Mertens, P. R. (2002). Mesangial cell gelatinase A synthesis is attenuated by oscillating hyperbaric pressure. Biochem. J., 362, 693-700.

Fahmi, H., Pelletier, J. P., Di Battista, J. A., Cheung, H. S., Fernandes, J. C., \& Martel-Pelletier, J. (2002). Peroxisome proliferator-activated receptor gamma activators inhibit MMP-1 production in human synovial fibroblasts likely by reducing the binding of the activator protein 1. Osteoarthritis Cartilage, 10, 100-108.

Flenniken, A. M., \& Williams, B. R. (1990). Developmental expression of the endogenous TIMP gene and a TIMP-lacZ fusion gene in transgenic mice. Genes Dev., 4, 1094-1106.

Fong, Y. C., Dutton, C. M., Cha, S. S., Garamszegi, N., Sim, F. H., \& Scully, S. P. (2004). Absence of a correlation between the presence of a single nucleotide polymorphism in the matrix metalloproteinase 1 promoter and outcome in patients of chondrosarcoma. Clin. Cancer Res., 10, 7329-7334.

Francois, M., Richette, P., Tsagris, L., Raymondjean, M., FulchignoniLataud, M. C., Forest, C., et al. (2004). Peroxisome proliferatoractivated receptor-gamma down-regulates chondrocyte matrix metalloproteinase-1 via a novel composite element. J. Biol. Chem., 279, 28411-28418.

Gardner, J., Borgmann, K., Deshpande, M. S., Dhar, A., Wu, L., Persidsky, R., et al. (2006). Potential mechanisms for astrocyte-TIMP-1 downregulation in chronic inflammatory diseases. J. Neurosci. Res., 83, 1281-1292.

Garneau, N. L., Wilusz, J., \& Wilusz, C. J. (2007). The highways and byways of mRNA decay. Nat. Rev. Mol. Cell. Biol., 8, 113-126.

Genin, P., Morin, P., \& Civas, A. (2003). Impairment of interferoninduced IRF-7 gene expression due to inhibition of ISGF3 formation by trichostatin A. J. Virol., 77, 7113-7119.

Gustavson, M. D., Crawford, H. C., Fingleton, B., \& Matrisian, L. M. (2004). Tcf binding sequence and position determines beta-catenin and Lef-1 responsiveness of MMP-7 promoters. Mol. Carcinog., 41, 125-139.

Haas, T. L., Stitelman, D., Davis, S. J., Apte, S. S., \& Madri, J. A. (1999). Egr-1 mediates extracellular matrix-driven transcription of membrane type 1 matrix metalloproteinase in endothelium. J. Biol. Chem., 274, 22679-22685.

Hall, M. C., Young, D. A., Waters, J. G., Rowan, A. D., Chantry, A., Edwards, D. R., et al. (2003). The comparative role of activator protein 1 and Smad factors in the regulation of Timp-1 and MMP1 gene expression by transforming growth factor-beta 1. J. Biol. Chem., 278, 10304-10313.

Hammani, K., Blakis, A., Morsette, D., Bowcock, A. M., Schmutte, C., Henriet, P., et al. (1996). Structure and characterization of the human tissue inhibitor of metalloproteinases-2 gene. J. Biol. Chem., 271, 25498-25505.

Harendza, S., Lovett, D. H., Panzer, U., Lukacs, Z., Kuhnl, P., \& Stahl, R. A. (2003). Linked common polymorphisms in the gelatinase a promoter are associated with diminished transcriptional response to estrogen and genetic fitness. J. Biol. Chem., 278, 20490-20499.

He, C. (1996). Molecular mechanism of transcriptional activation of human gelatinase B by proximal promoter. Cancer Lett., 106, 185-191.

Hettiaratchi, A., Hawkins, N. J., McKenzie, G., Ward, R. L., Hunt, J. E., Wakefield, D., et al. (2007). The collagenase-1 (MMP-1) gene promoter polymorphism-1607/2G is associated with favourable prognosis in patients with colorectal cancer. Br. J. Cancer, 96, 783-792.

Hill, M. R., Briggs, L., Montano, M. M., Estrada, A., Laurent, G. J., Selman, M., et al. (2004). Promoter variants in tissue inhibitor of metalloproteinase-3 (TIMP-3) protect against susceptibility in pigeon breeders' disease. Thorax, 59, 586-590.

Hirano, K., Sakamoto, T., Uchida, Y., Morishima, Y., Masuyama, K., Ishii, Y., et al. (2001). Tissue inhibitor of metalloproteinases-2 gene polymorphisms in chronic obstructive pulmonary disease. Eur. Respir. J., 18, 748-752.

Huang, T. S., Lee, C. C., Chang, A. C., Lin, S., Chao, C. C., Jou, Y. S., et al. (2003). Shortening of microsatellite deoxy(CA) repeats involved in GL331-induced down-regulation of matrix metalloproteinase-9 gene expression. Biochem. Biophys. Res. Commun., 300, 901-907.

Huang, W., Zhao, S., Ammanamanchi, S., Brattain, M., Venkatasubbarao, K., \& Freeman, J. W. (2005). Trichostatin A induces transforming growth factor beta type II receptor promoter activity and acetylation of Sp1 by recruitment of PCAF/p300 to a Sp1. NF-Y complex. J. Biol. Chem., 280, 10047-10054.

Huwiler, A., Akool el, S., Aschrafi, A., Hamada, F. M., Pfeilschifter, J., \& Eberhardt, W. (2003). ATP potentiates interleukin-1 betainduced MMP-9 expression in mesangial cells via recruitment of the ELAV protein HuR. J. Biol. Chem., 278, 51758-51769.

Ijpenberg, A., Tan, N. S., Gelman, L., Kersten, S., Seydoux, J., Xu, J., et al. (2004). In vivo activation of PPAR target genes by RXR homodimers. EMBO J, 23, 2083-2091.

Ivanova, T., Vinokurova, S., Petrenko, A., Eshilev, E., Solovyova, N., Kisseljov, F., et al. (2004). Frequent hypermethylation of 5' flanking region of TIMP-2 gene in cervical cancer. Int. J. Cancer, 108, $882-886$.

Jimenez, M. J., Balbin, M., Lopez, J. M., Alvarez, J., Komori, T., \& Lopez-Otin, C. (1999). Collagenase 3 is a target of Cbfa1, a transcription factor of the runt gene family involved in bone formation. Mol. Cell. Biol., 19, 4431-4442.

Ju, W., Kang, S., Kim, J. W., Park, N. H., Song, Y. S., Kang, S. B., et al. (2005). Promoter polymorphism in the matrix metalloproteinase-1 
and risk of cervical cancer in Korean women. Cancer Lett., 217, 191-196.

Kaneko, F., Saito, H., Saito, Y., Wakabayashi, K., Nakamoto, N., Tada, S., et al. (2004). Down-regulation of matrix-invasive potential of human liver cancer cells by type I interferon and a histone deacetylase inhibitor sodium butyrate. Int. J. Oncol., 24, 837-845.

Kiernan, R., Bres, V., Ng, R. W., Coudart, M. P., El Messaoudi, S., Sardet, C., et al. (2003). Post-activation turn-off of NF-kappa Bdependent transcription is regulated by acetylation of p65. J. Biol. Chem., 278, 2758-2766.

Klose, R. J., \& Bird, A. P. (2006). Genomic DNA methylation: The mark and its mediators. Trends Biochem. Sci., 31, 89-97.

Lal, A., Mazan-Mamczarz, K., Kawai, T., Yang, X., Martindale, J. L., \& Gorospe, M. (2004). Concurrent versus individual binding of HuR and AUF1 to common labile target mRNAs. EMBO J., 23, 3092-3102.

Leco, K. J., Apte, S. S., Taniguchi, G. T., Hawkes, S. P., Khokha, R., Schultz, G. A., et al. (1997). Murine tissue inhibitor of metalloproteinases-4 (Timp-4): cDNA isolation and expression in adult mouse tissues. FEBS Lett., 401, 213-217.

Lee, J. G., Dahi, S., Mahimkar, R., Tulloch, N. L., Alfonso-Jaume, M. A., Lovett, D. H., et al. (2005). Intronic regulation of matrix metalloproteinase-2 revealed by in vivo transcriptional analysis in ischemia. Proc. Natl. Acad. Sci. U.S.A., 102, 16345-16350.

Lewis, B. P., Shih, I. H., Jones-Rhoades, M. W., Bartel, D. P., \& Burge, C. B. (2003). Prediction of mammalian microRNA targets. Cell, 115, 787-798.

Logan, S. K., Garabedian, M. J., Campbell, C. E., \& Werb, Z. (1996). Synergistic transcriptional activation of the tissue inhibitor of metalloproteinases-1 promoter via functional interaction of AP-1 and Ets-1 transcription factors. J. Biol. Chem., 271, 774-782.

Lohi, J., Lehti, K., Valtanen, H., Parks, W. C., \& Keski-Oja, J. (2000). Structural analysis and promoter characterization of the human membrane-type matrix metalloproteinase-1 (MT1-MMP) gene. Gene, 242, 75-86.

Lu, J., Getz, G., Miska, E. A., Alvarez-Saavedra, E., Lamb, J., Peck, D., et al. (2005). MicroRNA expression profiles classify human cancers. Nature, 435, 834-838.

Ludwig, M. G., Basset, P., \& Anglard, P. (2000). Multiple regulatory elements in the murine stromelysin-3 promoter. Evidence for direct control by CCAAT/enhancer-binding protein beta and thyroid and retinoid receptors. J. Biol. Chem., 275, 39981-39990.

Ma, Z., Chang, M. J., Shah, R., Adamski, J., Zhao, X., \& Benveniste, E. N. (2004). Brg-1 is required for maximal transcription of the human matrix metalloproteinase-2 gene. J. Biol. Chem., 279, 46326-46334.

Ma, Z., Shah, R. C., Chang, M. J., \& Benveniste, E. N. (2004). Coordination of cell signaling, chromatin remodeling, histone modifications, and regulator recruitment in human matrix metalloproteinase 9 gene transcription. Mol. Cell. Biol., 24, 5496-5509.

Mader, S., Leroy, P., Chen, J. Y., \& Chambon, P. (1993). Multiple parameters control the selectivity of nuclear receptors for their response elements. Selectivity and promiscuity in response element recognition by retinoic acid receptors and retinoid X receptors. $J$. Biol. Chem., 268, 591-600.

Malik, M. H., Jury, F., Bayat, A., Ollier, W. E., \& Kay, P. R. (2007). Genetic susceptibility to total hip arthroplasty failure: A preliminary study on the influence of matrix metalloproteinase 1 , interleukin 6 polymorphisms and vitamin D receptor. Ann. Rheum. Dis., 66, 1116-1120.

Mangelsdorf, D. J., Umesono, K., Kliewer, S. A., Borgmeyer, U., Ong, E. S., \& Evans, R. M. (1991). A direct repeat in the cellular retinol- binding protein type II gene confers differential regulation by RXR and RAR. Cell, 66, 555-561.

Marchenko, G. N., Marchenko, N. D., Leng, J., \& Strongin, A. Y. (2002). Promoter characterization of the novel human matrix metalloproteinase-26 gene: Regulation by the T-cell factor- 4 implies specific expression of the gene in cancer cells of epithelial origin. Biochem. J., 363, 253-262.

Martens, J. H., Verlaan, M., Kalkhoven, E., \& Zantema, A. (2003). Cascade of distinct histone modifications during collagenase gene activation. Mol. Cell. Biol., 23, 1808-1816.

Mengshol, J. A., Vincenti, M. P., \& Brinckerhoff, C. E. (2001). IL1 induces collagenase-3 (MMP-13) promoter activity in stably transfected chondrocytic cells: Requirement for Runx-2 and activation by p38 MAPK and JNK pathways. Nucleic Acids Res., 29, 4361-4372.

Ning, W., Dong, Y., Sun, J., Li, C., Matthay, M. A., FeghaliBostwick, C. A., et al. (2007). Cigarette smoke stimulates matrix metalloproteinase-2 activity via EGR-1 in human lung fibroblasts. Am. J. Respir. Cell. Mol. Biol., 36, 480-490.

Nusinzon, I., \& Horvath, C. M. (2003). Interferon-stimulated transcription and innate antiviral immunity require deacetylase activity and histone deacetylase 1. Proc. Natl. Acad. Sci. U.S.A., 100, 14742-14747.

Nuttall, R. K., Sampieri, C. L., Pennington, C. J., Gill, S. E., Schultz, G. A., \& Edwards, D. R. (2004). Expression analysis of the entire MMP and TIMP gene families during mouse tissue development. FEBS Lett., 563, 129-134.

Ortega, N., Behonick, D. J., \& Werb, Z. (2004). Matrix remodeling during endochondral ossification. Trends Cell. Biol., 14, 8693.

Overall, C. M., \& Lopez-Otin, C. (2002). Strategies for MMP inhibition in cancer: Innovations for the post-trial era. Nat. Rev. Cancer., 2, 657-672.

Pender, S. L., Quinn, J. J., Sanderson, I. R., \& MacDonald, T. T. (2000). Butyrate upregulates stromelysin-1 production by intestinal mesenchymal cells. Am. J. Physiol. Gastrointest. Liver Physiol., 279, G918-G924.

Phillips, B. W., Sharma, R., Leco, P. A., \& Edwards, D. R. (1999). A sequence-selective single-strand DNA-binding protein regulates basal transcription of the murine tissue inhibitor of metalloproteinases-1 (Timp-1) gene. J. Biol. Chem., 274, 22197-22207.

Porte, D., Tuckermann, J., Becker, M., Baumann, B., Teurich, S., Higgins, T., et al. (1999). Both AP-1 and Cbfa1-like factors are required for the induction of interstitial collagenase by parathyroid hormone. Oncogene, 18, 667-678.

Pratap, J., Javed, A., Languino, L. R., van Wijnen, A. J., Stein, J. L., Stein, G. S., et al. (2005). The Runx2 osteogenic transcription factor regulates matrix metalloproteinase 9 in bone metastatic cancer cells and controls cell invasion. Mol. Cell. Biol., 25, 85818591.

Price, S. J., Greaves, D. R., \& Watkins, H. (2001). Identification of novel, functional genetic variants in the human matrix metalloproteinase-2 gene: Role of $\mathrm{Sp} 1$ in allele-specific transcriptional regulation. J. Biol. Chem., 276, 7549-7558.

Qin, H., Sun, Y., \& Benveniste, E. N. (1999). The transcription factors Sp1, Sp3, and AP-2 are required for constitutive matrix metalloproteinase-2 gene expression in astroglioma cells. J. Biol. Chem., 274, 29130-29137.

Quivy, V., \& Van Lint, C. (2004). Regulation at multiple levels of NFkappaB-mediated transactivation by protein acetylation. Biochem. Pharmacol., 68, 1221-1229. 
Rascle, A., Johnston, J. A., \& Amati, B. (2003). Deacetylase activity is required for recruitment of the basal transcription machinery and transactivation by STAT5. Mol. Cell. Biol., 23, 4162-4173.

Reunanen, N., Li, S. P., Ahonen, M., Foschi, M., Han, J., \& Kahari, V. M. (2002). Activation of $\mathrm{p} 38$ alpha MAPK enhances collagenase-1 (matrix metalloproteinase (MMP)-1) and stromelysin-1 (MMP3) expression by mRNA stabilization. J. Biol. Chem., 277, 32360-32368.

Roach, H. I., Yamada, N., Cheung, K. S., Tilley, S., Clarke, N. M., Oreffo, R. O., et al. (2005). Association between the abnormal expression of matrix-degrading enzymes by human osteoarthritic chondrocytes and demethylation of specific $\mathrm{CpG}$ sites in the promoter regions. Arthritis Rheum., 52, 3110-3124.

Rutter, J. L., Mitchell, T. I., Buttice, G., Meyers, J., Gusella, J. F., Ozelius, L. J., et al. (1998). A single nucleotide polymorphism in the matrix metalloproteinase-1 promoter creates an Ets binding site and augments transcription. Cancer Res., 58, 5321-5325.

Rydziel, S., Delany, A. M., \& Canalis, E. (2004). AU-rich elements in the collagenase 3 mRNA mediate stabilization of the transcript by cortisol in osteoblasts. J. Biol. Chem., 279, 5397-5404.

Sakamoto, S., Potla, R., \& Larner, A. C. (2004). Histone deacetylase activity is required to recruit RNA polymerase II to the promoters of selected interferon-stimulated early response genes. J. Biol. Chem., 279, 40362-40367.

Sampieri, C. L., Nuttall, R. K., Young, D. A., Goldspink, D., Clark, I. M., \& Edwards, D. R. (2008). Activation of p38 and JNK MAP kinase pathways abrogates requirement for new protein synthesis for phorbol ester mediated induction of select MMP and TIMP genes. Matrix Biol., 27, 128-138.

Samuel, S., Twizere, J. C., Beifuss, K. K., \& Bernstein, L. R. (2008). Nucleolin binds specifically to an AP-1 DNA sequence and represses AP1-dependent transactivation of the matrix metalloproteinase-13 gene. Mol. Carcinog., 47, 34-36.

Selvamurugan, N., Jefcoat, S. C., Kwok, S., Kowalewski, R., Tamasi, J. A., \& Partridge, N. C. (2006). Overexpression of Runx2 directed by the matrix metalloproteinase- 13 promoter containing the AP-1 and Runx/RD/Cbfa sites alters bone remodeling in vivo. J. Cell. Biochem., 99, 545-557.

Shimajiri, S., Arima, N., Tanimoto, A., Murata, Y., Hamada, T., Wang, K. Y., et al. (1999). Shortened microsatellite d(CA)21 sequence down-regulates promoter activity of matrix metalloproteinase 9 gene. FEBS Lett., 455, 70-74.

Shukeir, N., Pakneshan, P., Chen, G., Szyf, M., \& Rabbani, S. A. (2006). Alteration of the methylation status of tumor-promoting genes decreases prostate cancer cell invasiveness and tumorigenesis in vitro and in vivo. Cancer Res., 66, 9202-9210.

Song, Y., Qian, L., Song, S., Chen, L., Zhang, Y., Yuan, G., et al. (2008). Fra-1 and Stat 3 synergistically regulate activation of human MMP-9 gene. Mol. Immunol., 45, 137-143.

Sun, Y., Hegamyer, G., Kim, H., Sithanandam, K., Li, H., Watts, R., et al. (1995). Molecular cloning of mouse tissue inhibitor of metalloproteinases- 3 and its promoter. Specific lack of expression in neoplastic JB6 cells may reflect altered gene methylation. J. Biol. Chem., 270, 19312-19319.

Takahashi, M., Tsunoda, T., Seiki, M., Nakamura, Y., \& Furukawa, Y. (2002). Identification of membrane-type matrix metalloproteinase1 as a target of the beta-catenin/Tcf 4 complex in human colorectal cancers. Oncogene, 21, 5861-5867.

Tower, G. B., Coon, C. I., Belguise, K., Chalbos, D., \& Brinckerhoff, C. E. (2003). Fra- 1 targets the AP- 1 site/2G single nucleotide polymorphism (ETS site) in the MMP-1 promoter. Eur. J. Biochem., $270,4216-4225$.
Trim, J. E., Samra, S. K., Arthur, M. J., Wright, M. C., McAulay, M., Beri, R., et al. (2000). Upstream tissue inhibitor of metalloproteinases-1 (TIMP-1) element-1, a novel and essential regulatory DNA motif in the human TIMP-1 gene promoter, directly interacts with a $30-\mathrm{kDa}$ nuclear protein. J. Biol. Chem., 275, 6657-6663.

Vincenti, M. P., \& Brinckerhoff, C. E. (2002). Transcriptional regulation of collagenase (MMP-1, MMP-13) genes in arthritis: Integration of complex signaling pathways for the recruitment of gene-specific transcription factors. Arthritis Res., 4, 157-164.

Vincenti, M. P., \& Brinckerhoff, C. E. (2007). Signal transduction and cell-type specific regulation of matrix metalloproteinase gene expression: Can MMPs be good for you? J. Cell. Physiol., 213, 355-364.

Vincenti, M. P., White, L. A., Schroen, D. J., Benbow, U., \& Brinckerhoff, C. E. (1996). Regulating expression of the gene for matrix metalloproteinase-1 (collagenase): Mechanisms that control enzyme activity, transcription, and mRNA stability. Crit. Rev. Eukaryot. Gene Exp., 6, 391-411.

Vincenti, M. P., Coon, C. I., \& Brinckerhoff, C. E. (1998). Nuclear factor kappaB/p50 activates an element in the distal matrix metalloproteinase 1 promoter in interleukin-1beta-stimulated synovial fibroblasts. Arthritis Rheum., 41, 1987-1994.

Volinia, S., Calin, G. A., Liu, C. G., Ambs, S., Cimmino, A., Petrocca, F., et al. (2006). A microRNA expression signature of human solid tumors defines cancer gene targets. Proc. Natl. Acad. Sci. U.S.A., 103, 2257-2261.

Vries, R. G., Prudenziati, M., Zwartjes, C., Verlaan, M., Kalkhoven, E., \& Zantema, A. (2001). A specific lysine in c-Jun is required for transcriptional repression by E1A and is acetylated by $\mathrm{p} 300$. EMBO J., 20, 6095-6103.

Weiss, C., Schneider, S., Wagner, E. F., Zhang, X., Seto, E., \& Bohmann, D. (2003). JNK phosphorylation relieves HDAC3dependent suppression of the transcriptional activity of c-Jun. EMBO J., 22, 3686-3695.

Westermarck, J., Seth, A., \& Kahari, V. M. (1997). Differential regulation of interstitial collagenase (MMP-1) gene expression by ETS transcription factors. Oncogene, 14, 2651-2660.

Westermarck, J., Li, S. P., Kallunki, T., Han, J., \& Kahari, V. M. (2001). p38 mitogen-activated protein kinase-dependent activation of protein phosphatases 1 and 2A inhibits MEK1 and MEK2 activity and collagenase 1 (MMP-1) gene expression. Mol. Cell. Biol., 21, 2373-2383.

White, L. A., \& Brinckerhoff, C. E. (1995). Two activator protein-1 elements in the matrix metalloproteinase-1 promoter have different effects on transcription and bind Jun D, c-Fos, and Fra-2. Matrix Biol., 14, 715-725.

Wick, M., Haronen, R., Mumberg, D., Burger, C., Olsen, B. R., Budarf, M. L., et al. (1995). Structure of the human TIMP-3 gene and its cell cycle-regulated promoter. Biochem. J., 311(Pt 2), 549-554.

Xie, T. X., Wei, D., Liu, M., Gao, A. C., Ali-Osman, F., Sawaya, R., et al. (2004). Stat 3 activation regulates the expression of matrix metalloproteinase-2 and tumor invasion and metastasis. Oncogene, $23,3550-3560$.

Yamaguchi, K., Lantowski, A., Dannenberg, A. J., \& Subbaramaiah, K. (2005). Histone deacetylase inhibitors suppress the induction of c-Jun and its target genes including COX-2. J. Biol. Chem.

Yan, C., \& Boyd, D. D. (2007). Regulation of matrix metalloproteinase gene expression. J. Cell. Physiol., 211, 19-26.

Yan, C., Wang, H., \& Boyd, D. D. (2002). ATF3 represses 72-kDa type IV collagenase (MMP-2) expression by antagonizing p53- 
dependent trans-activation of the collagenase promoter. J. Biol. Chem., 277, 10804-10812.

Yan, C., Wang, H., Toh, Y., \& Boyd, D. D. (2003). Repression of 92$\mathrm{kDa}$ type IV collagenase expression by MTA1 is mediated through direct interactions with the promoter via a mechanism, which is both dependent on and independent of histone deacetylation. $J$. Biol. Chem., 278, 2309-2316.

Yang, S. H., \& Sharrocks, A. D. (2004). SUMO promotes HDACmediated transcriptional repression. Mol. Cell., 13, 611-617.

Ye, S. (2006). Influence of matrix metalloproteinase genotype on cardiovascular disease susceptibility and outcome. Cardiovasc. Res., 69, 636-645.

Ye, S., Eriksson, P., Hamsten, A., Kurkinen, M., Humphries, S. E., \& Henney, A. M. (1996). Progression of coronary atherosclerosis is associated with a common genetic variant of the human stromelysin-1 promoter which results in reduced gene expression. J. Biol. Chem., 271, 13055-13060.

Young, D. A., Phillips, B. W., Lundy, C., Nuttall, R. K., Hogan, A., Schultz, G. A., et al. (2002). Identification of an initiatorlike element essential for the expression of the tissue inhibitor of metalloproteinases-4 (Timp-4) gene. Biochem. J., 364, 8999.

Young, D. A., Billingham, O., Sampieri, C. L., Edwards, D. R., \& Clark, I. M. (2005). Differential effects of histone deacetylase inhibitors on phorbol ester- and TGF-beta1 induced murine tissue inhibitor of metalloproteinases-1 gene expression. FEBS J., 272, 1912 1926.

Young, D. A., Lakey, R. L., Pennington, C. J., Jones, D., Kevorkian, L., Edwards, D. R., et al. (2005). Histone deacetylase inhibitors modulate metalloproteinase gene expression in chondrocytes and block cartilage resorption. Arthritis Res. Ther, 7, R503-R512.

Yuan, B. Z., Jefferson, A. M., Popescu, N. C., \& Reynolds, S. H. (2004). Aberrant gene expression in human non small cell lung carcinoma cells exposed to demethylating agent 5 -aza-2'-deoxycytidine. Neoplasia, 6, 412-419.

Yuan, Z. L., Guan, Y. J., Chatterjee, D., \& Chin, Y. E. (2005). Stat3 dimerization regulated by reversible acetylation of a single lysine residue. Science, 307, 269-273.

Zhang, B., Ye, S., Herrmann, S. M., Eriksson, P., de Maat, M., Evans, A., et al. (1999). Functional polymorphism in the regulatory region of gelatinase B gene in relation to severity of coronary atherosclerosis. Circulation, 99, 1788-1794.

Zhang, Y., Li, W., Chi, H. S., Chen, J., \& Denbesten, P. K. (2007). JNK/c-Jun signaling pathway mediates the fluoride-induced downregulation of MMP-20 in vitro. Matrix Biol., 26, 633-641.

Zhong, Z. D., Hammani, K., Bae, W. S., \& DeClerck, Y. A. (2000). NF$\mathrm{Y}$ and Sp1 cooperate for the transcriptional activation and cAMP response of human tissue inhibitor of metalloproteinases-2. J. Biol. Chem., 275, 18602-18610.

Zhou, Y., Yu, C., Miao, X., Tan, W., Liang, G., Xiong, P., et al. (2004). Substantial reduction in risk of breast cancer associated with genetic polymorphisms in the promoters of the matrix metalloproteinase- 2 and tissue inhibitor of metalloproteinase-2 genes. Carcinogenesis, 25, 399-404.

Zhu, Y., Spitz, M. R., Lei, L., Mills, G. B., \& Wu, X. (2001). A single nucleotide polymorphism in the matrix metalloproteinase1 promoter enhances lung cancer susceptibility. Cancer Res., 61, 7825-7829. 